Vieira, G.D.; Bulhões, N.G.; Bulhões, T.G. Paisagens do ecoturismo na estrada real: reflexão sobre o planejamento e gestão do segmento no Polo Diamantina (MG). Revista Brasileira de Ecoturismo, São Paulo, v.6, n.4, nov-2013, pp.157-175.

\title{
Paisagens do ecoturismo na estrada real: reflexão sobre o planejamento e gestão do segmento no Polo Diamantina (MG)
}

\author{
Landscapes of ecotourism on the Royal Road: reflection about the planning \\ and management of segment in Polo Diamantina (MG)

\section{Gabriela Duarte Vieira, Nauê Gonçalves Bulhões, Tainá Gonçalves Bulhões}

\section{RESUMO}

A Estrada Real foi o antigo caminho aberto para escoamento do ouro e diamante até o litoral para envio à Coroa Portuguesa, sua riqueza histórica e importância para história do Brasil já são comprovadas e muito estudadas, também já se tem conhecimento do potencial para o turismo de aventura e ecoturismo. $\mathrm{O}$ artigo apresenta um histórico de criação deste caminho bem como sobre sua gestão feita pelo Instituto Estrada Real. A análise fica por conta do diagnosticado da gestão do ecoturismo, no que diz respeito à sua comercialização, na primeira porção do Caminho dos Diamantes da Estrada Real, que vai de Diamantina a Alvorada de Minas. A intenção do artigo é diagnosticar a situação atual da gestão e comercialização do ecoturismo bem como apontar o grande potencial que há para ser trabalhado, assim apresentamos quais atrativos são comercializados e de que forma, a que atividade do ecoturismo é vinculada e são identificados quais atrativos e atividades têm potencial turístico e ainda não são trabalhados.

PALAVRAS-CHAVE: Estrada Real; Ecoturismo; Gestão, Comercialização e Atividades do Ecoturismo.

\section{ABSTRACT}

The Royal Road was the old way open for the flow of gold and diamond until the coast for shipment to the Portuguese Crown, and its historical importance to the history of Brazil are already proven and widely studied, also already aware of the potential for adventure tourism and ecotourism. The article presents a history of the creation of this path as well as its management by The Royal Road Institute (IER). The analysis is for the diagnosis of ecotourism management, with respect to its marketing, the first portion of the path of Diamond's Path, which runs from Diamantina to Alvorada de Minas. Here attractions which are marketed and how the ecotourism activity that is linked and are identified attractions and activities which have tourism potential and are not yet worked.

KEYWORDS: Royal Road; Ecotourism; Management; Marketing and Ecotourism Activities. 
Paisagens do ecoturismo na estrada real: reflexão sobre o planejamento e gestão do segmento no Polo Diamantina (MG)

\section{Introdução}

As estradas reais foram consideras as principais vias abertas para dominação do interior do Brasil colônia, como o objetivo de controlar a circulação de pessoas e fiscalizar a extração das riquezas (MARQUES, 2009). Sendo então, esses caminhos construídos no contexto de riquezas do período colonial, tendo como pontos principais cidades que fazem parte, e são necessárias, na história do Brasil, como Ouro Preto, Tiradentes, Diamantina e Paraty.

Em 1999 é criado pela Federação das Indústrias de Minas Gerais - FIEMG o Instituto Estrada Real, com o objetivo de transformar a antiga estrada em uma rota turística, considerada hoje como o maior completo turístico do país.

Para o Instituto, a Estrada Real abrange 199 municípios, sendo a maioria no estado de Minas Gerais, São Paulo e Rio de Janeiro. O caminho principal passa por 87 cidades e distritos, sendo 76 em Minas Gerais, 3 em São Paulo e 8 no Rio de Janeiro, tem mais de 1,6 mil quilômetros de extensão. Toda essa área é dividida em quatro caminhos, o Velho, o Novo, o de Sabarabuçu e o Caminho dos Diamantes.

Durante o período colonial quando a sua riqueza mineral construiu o notável caminho da Estrada Real, os mais expressivos naturalistas da época por ali passaram e nos legaram extraordinárias descrições e afrescos de sua exuberante paisagem.

O Caminho dos Diamantes foi escolhido para a realização desta análise de vido a relevante expressão de suas paisagens naturais, que se revelam em atrativos turísticos que somam aventura, natureza, história e cultura. Dentro deste caminho foi selecionado o recorte no polo Diamantina, considerado apenas o eixo principal da Estrada Real, que passa pelos municípios de Diamantina, Serro e Alvorada de Minas o que corresponde a aproximadamente cem quilômetros.

Este trajeto está localizado na Serra do Espinhaço, que é reconhecida pela UNESCO como Reserva da Biosfera Mundial. O patrimônio natural da Serra do Espinhaço é singular devido às ricas representações de plantas, animais e rituais, sendo diversas espécies endêmicas, apresenta ainda inscrições rupestres dos períodos mais antigos da ocupação ameríndia, e representativos cursos d'agua encontradas por toda a extensão da Reserva.

O artigo não faz uma análise aprofundada da paisagem, considerando a complexidade de seu conceito, consideramos paisagem como uma categoria de estudo da geografia que permite uma avaliação a partir de uma imagem que pode ser contemplada por meio da observação. Sendo assim, o artigo pretende apenas por meio da observação identificar as características da paisagem da região tendo em vista a prática do ecoturismo, ou seja, apontar atividades do ecoturismo que tem condições de serem desenvolvidas na região devido a suas peculiaridades.

Baseado nos atrativos de ecoturismo que Instituto Estrada Real apresenta em seu site e na análise das formas em que estes atrativos são comercializados pelos receptivos locais, será possível o diagnóstico do planejamento turístico realizado e o levantamento das potencialidades ainda não exploradas. Indicando, dessa forma o potencial ecoturístico da região. 
Vieira, G.D.; Bulhões, N.G.; Bulhões, T.G.

\title{
A Estrada Real e sua Gestão
}

Com a notícia da descoberta de um novo território os portugueses foram ocupando o litoral do país e por isso a princípio apenas a costa foi sendo desbravada e colonizada, tendo em vista as diversas tentativas de invasão sofridas por holandeses, espanhóis e franceses, por exemplo, além das tentativas fracassadas de algumas bandeiras.

Cerca de 50 anos após o descobrimento por Pedro Alvares Cabral o território foi dividido em capitanias hereditárias que considerava uma extensa área interna, que foi sendo adentrada em busca de locais para o cultivo da cana de açúcar. Apenas no final do século XVII o tão procurado ouro foi descoberto na região nas Minas Gerais, Goiás e Mato Grosso. Foi a partir daí que as viagens e ocupação do interior do Brasil têm inicio.

\begin{abstract}
Apenas no último quartel do século XVII, foram descobertas as primeiras minas pelos bandeirantes, nas regiões onde hoje se situam os municípios de Sabará, Ouro Preto e Mariana. O ouro era abundante nos cursos de água da região das Minas Gerais, trazendo um grande fluxo de pessoas para o interior da colônia, o que ocasionou a formação de vários núcleos urbanos. Este movimento de intensificou no início do século XVIII com a descoberta dos diamantes na região do atual município de Diamantina (MARQUES, 2009, p.181 apud INSTITUTO ESTRADA REAL; INSTITUTO TERRA AZUL, 2006, p.2).
\end{abstract}

Quando a notícia chega à Portugal, a Coroa logo começa a fiscalização dos caminhos já abertos e ordena a abertura de novos caminhos, as estradas reais, que foram consideras as principais vias da colônia, como o objetivo de controlar a circulação de pessoas e fiscalizar a extração das riquezas "estabeleceu caminhos oficiais (estradas reais), que se tornariam as únicas vias autorizadas para a circulação de pessoas, mercadorias, ouro e diamante" (MARQUES, 2009, p.182). Marques (2009) encontra um conceito para termo Estrada Real que é usado desde os anos 1600 que é descrito por Renger (2007) como referencia.

Aos caminhos do período colonial onde o poder do Estado de fez presente em forma de registros ou outros pontos de cobrança, seja de pedágios, dos direitos de entrada, seja do quinto do Ouro. Assim, nas Minas, as Estradas Reais surgiram em decorrência da inserção do interior do Brasil na política fiscal exercida pela Colônia. Nas Minas, o objetivo primordial do controle dos caminhos era a arrecadação dos quintos de ouro, sempre confiada a funcionários régios (...) Formalizase, assim, a aplicação do título Estrada Real aos caminhos de Minas, como um conceito fiscal (MARQUES, 2009, p.182 apud RENGER, 2007, p.135).

Por isso o povoamento da região foi intenso, sendo formada tanto por pessoas que tinham autorização para extração de ouro e diamantes e seus diversos escravos como pessoas que vieram para lucrar com hospedarias para os diversos viajantes e 
Paisagens do ecoturismo na estrada real: reflexão sobre o planejamento e gestão do segmento no Polo Diamantina (MG)

suas bandeiras e também com o comercio ilegal das pedras preciosas. Segundo Marques (2009, p.181 apud INSTITUTO ESTRADA REAL; INSTITUTO TERRA AZUL, 2006, p.04), "em 1700, a estimativa populacional alcançava 30 mil pessoas nas regiões das minas, contra 500 mil na colônia, sem contar a população indígena" população essa responsável por abrir as primeiras trilhas que deram origem aos caminhos oficiais.

Sendo então, esses caminhos mineiros, construídos em todo um contexto de riquezas do período colonial, tendo como pontos principais cidades que fazem parte, e são necessárias, na história do Brasil, como Ouro Preto, Tiradentes, Diamantina e Paraty, além de estar inserido em um meio ambiente riquíssimo e de extrema beleza, em 1999 é criado pela Federação das Indústrias de Minas Gerais - FIEMG o Instituto Estrada Real, com o objetivo de transformar a antiga estrada em uma rota turística, considerada hoje como o maior completo turístico do país.

\begin{abstract}
O Instituto Estrada Real é uma entidade criada em 1999 pelo Sistema FIEMG, que tem por objetivos organizar, fomentar e gerenciar o produto turístico Estrada Real. Com uma equipe multidisciplinar especializada em turismo, transformou o antigo caminho, aberto há mais de 300 anos pela Coroa Portuguesa, em um destino reconhecido no Brasil e no exterior. A Estrada Real é a maior rota turística do país. São mais de 1.630 km de extensão, passando por Minas Gerais, Rio de Janeiro e São Paulo (INSTITUTO ESTRADA REAL, 2013 ${ }^{1}$ ).
\end{abstract}

Para o Instituto, a Estrada Real abrange 199 municípios, sendo cento e sessenta e nove de Minas Gerais, vinte e duas de São Paulo e oito do Rio de Janeiro, que equivalem a mais de 80 mil quilômetros quadrados de área de influência da Estrada Real. O eixo principal que é o caminho, o percurso, passa por 87 cidades e distritos, sendo 76 em Minas Gerais, 3 em São Paulo e 8 no Rio de Janeiro, tem mais de 1,6 mil quilômetros de extensão. Toda essa área é dividida em quatro caminhos, o Velho, o Novo, o de Sabarabuçu e o Caminho dos Diamantes.

O Caminho Velho, o mais antigo, foi a primeira rota para se chegar e sair da região de Vila Rica, atual Ouro Preto, sendo assim são $710 \mathrm{~km}$ que ligam Ouro Preto à Paraty, passando pela região de Tiradentes e o sul de Minas. O Caminho de Sabarabuçu pode ser considerado como uma extensão ao Caminho Velho que o liga ao Caminho dos Diamantes tem como um dos pontos principais a cidade de Sabará que fica no meio dos $160 \mathrm{~km}$ da extensão desse caminho.

O Caminho Novo é o caminho que pode ser considerado como a verdadeira Estrada Real, já que foi o único trecho aberto exclusivamente devido à uma ordem da Coroa Portuguesa para aumentar a fiscalização, controlar o contrabando e garantir um escoamento mais rápido das riquezas extraídas nas Minas Gerais, são 515 km que ligam Ouro Preto ao Rio de Janeiro.

As constantes revoltas ocorridas na região aurífera, somadas ao freqüente e intenso contrabando que se praticava com o ouro extraído das minas gerias, levaram o então governador da Capitania do Rio de 
Janeiro, Artur de Sá de Menezes, a planejar já em 1968, um caminho mais curto e seguro entre a região mineradora e a cidade do Rio de Janeiro. (...) Assim, em outubro de 1968, a Coroa acatou a indicação. (INSTITUTO ESTRADA REAL, 2005, p. 20).

Os $395 \mathrm{~km}$ do Caminho dos Diamantes foram os mais fiscalizados pela Coroa Portuguesa, para sair de Ouro Preto com destino à Diamantina era necessária uma autorização, e para entrar na cidade a autorização deveria ser analisada pela autoridade local, o intendente-geral, como descreve Spix e Martius (1981, p.26).

Como por uma ordem régia, a entrada no Distrito Diamantino, que começa a umas cinco léguas daqui só é permitida se o intendente-geral dele autoriza por escrito o registro, o ouvidor teve a bondade de mandar um mensageiro especial (pedestre) a Tejuco com nosso requerimento, junto a licença do rei.

Além de toda fortuna a Estrada Real é rica também por sua história e cultura, porém o foco deste trabalho é riqueza natural, as paisagens que compõe a Estrada Real.

Assim, não consideramos toda a extensão da Estrada Real no artigo, foi considerado apenas o Polo Diamantina do Caminho dos Diamantes. O Polo abrange 14 municípios, sendo eles: São Gonçalo do Rio Preto, Couto de Magalhães de Minas, Felício dos Santos, Santo Hipólito, Monjolos, Gouveia, Datas, Presidente Kubitscheck, Serra Azul de Minas, Santo Antônio do Itambé, Sabinópolis, Alvorada de Minas, Serro e Diamantina (Figura 1).

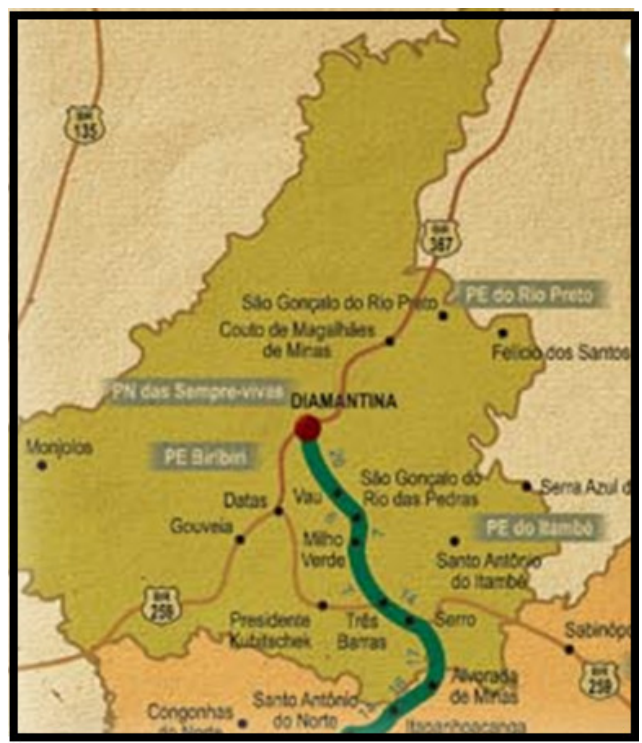

Figura 1: Recorte do Polo Diamantina no caminho dos diamantes da Estrada Real.

Figure 1: Cut the Polo Diamantina in the path of diamonds Royal Road.

Fonte: www.estradareal.org.br.

Source: www.estradareal.org.br. 
Paisagens do ecoturismo na estrada real: reflexão sobre o planejamento e gestão do segmento no Polo Diamantina (MG)

Entretanto, não foi feita uma análise da paisagem e potencial do ecoturismo de todo o polo, foi considerado apenas o eixo principal da Estrada Real, que passa pelos municípios de Diamantina, Serro e Alvorada de Minas o que corresponde a aproximadamente cem quilômetros.

\section{Ecoturismo}

Em 1994, o Ministério da Indústria, Comércio e Turismo (MICT) e o Ministério do Meio Ambiente e da Amazônia Legal (MMA), em conjunto com representantes do Instituto Brasileiro de Turismo (EMBRATUR) e do Instituto Brasileiro do Meio Ambiente e dos Recursos Naturais Renováveis (IBAMA), além de empresários e consultores da área, criaram as Diretrizes para a Política Nacional de Ecoturismo e estabeleceram o seguinte conceito para a atividade:

Segmento da atividade turística que utiliza, de forma sustentável, o patrimônio natural e cultural, incentiva sua conservação e busca a formação de uma consciência ambientalista através da interpretação do ambiente, promovendo o bem estar das populações (BRASIL, 1994, p.19).

De acordo com essa definição, percebe-se que o ecoturismo precisa ser praticado de forma sustentável, sendo que as atividades devem contribuir para a conservação da natureza e ações de sensibilização e conscientização devem ser propostas aos praticantes, para que os mesmos sejam informados quanto à importância das áreas preservadas. É fundamental o envolvimento da comunidade em todas as etapas de implantação e sua participação deve ser efetiva (VIEIRA, 2012).

De acordo com o Ministério do Turismo - MTUR (2010, p 21):

[...] o ecoturismo pode ser entendido como as atividades turísticas baseadas na relação sustentável com a natureza e as comunidades receptoras, comprometidas com a conservação, a educação ambiental e o desenvolvimento socioeconômico.

Buscando outros conceitos de ecoturismo é possível perceber que esses são diversos, mas ainda não existe uma definição única aceita por todos. Sabe-se que a razão de ser do ecoturismo é a preocupação com o meio ambiente. O prefixo "eco" tem sido muito utilizado como bandeira em todo movimento que tenha apelo ambientalista, embora nem sempre ele seja utilizado com o real comprometimento do significado do mesmo (VIEIRA, 2012).

Ainda sobre a origem dos termos ligados a esse tipo de turismo, Moraes (2000) ressalta que as raízes do ecoturismo encontram-se na natureza e no turismo ao ar livre. Os visitantes que há mais de um século chegaram em massa ao Parque Nacional de Yellowstone (nos Estados Unidos da América) foram os primeiros ecoturistas do mundo. 
Segundo Mourão (2004), apesar da origem do termo ecoturismo ser controversa e não muito clara, especula-se que o termo foi utilizado pela primeira vez por W. Hetzer, em 1965, identificando os quatro princípios para o turismo responsável: respeitar as culturas locais, minimizar impactos ambientais, maximizar a satisfação do visitante e maximizar os benefícios para comunidades locais. Segundo Bernaldez (1994 apud CÉSAR, 2007, p.8), o "ecoturismo surgiu devido a alguns problemas causados pelo turismo de massa".

Os primeiros praticantes do ecoturismo não estavam interessados nos padrões de consumo do turismo de massa, ocorrendo assim a renovação da atividade após a década de 1980.

A Conferência das Nações Unidas sobre meio ambiente na cidade do Rio de Janeiro, em 1992, consolidou o termo desenvolvimento sustentável, estimulando o interesse e o grande crescimento do ecoturismo como uma estratégia de desenvolvimento sustentável (CÉSAR, 2007). Nesse contexto, outro marco temporal, foi o ano de 2002, eleito o Ano Internacional do Ecoturismo. Segundo Rodrigues (2003), foi um ano também emblemático na história das discussões de cunho ecológico, pelo fato de ter completado dez anos da realização da Eco-92, momento de grande ebulição em torno da Cúpula Mundial Rio+10, em Johannesburgo, África do Sul ${ }^{2}$. Já no ano de 2012, foi realizada entre os dias 13 e 22 de junho, na cidade do Rio de Janeiro, a Conferência das Nações Unidas sobre Desenvolvimento Sustentável (CNUDS), conhecida também como Rio+20, cujo objetivo principal foi discutir sobre a renovação do compromisso político com o desenvolvimento sustentável. (VIEIRA, 2012)

Mitraud (2003, p.11) ressalta que "dentro dos diversos segmentos turísticos, o ecoturismo vem sendo apontado como aquele que apresenta os mais altos índices de crescimento, com um aumento de demanda variando de 10 a 20\% ao ano, de acordo com diversos estudos".

É notável que o ecoturismo e o turismo de aventura vêm crescendo em larga escala no mundo, portanto, é de suma urgência que os agentes, agências, operadoras de ecoturismo e o poder público deem maior atenção para que a atividade cresça de forma controlada e acompanhe o ritmo acelerado de crescimento da atividade em todo o mundo.

Por ser o ecoturismo uma atividade recente e em expansão, necessita ser monitorada de perto para que a mesma possa ser desenvolvida de forma organizada e responsável, havendo a necessidade de preparar o ecoturista para o contato com a natureza, sem depredá-la.

\section{O ecoturismo em Diamantina e Região}

Considerando as reflexões apresentadas à luz do objeto de estudo desse trabaIho - o ecoturismo em Diamantina - é interessante considerar essa atividade frente ao ecossistema do cerrado brasileiro, conforme apresentado por Neiman e Rabinovici (2002, p.154). 
Paisagens do ecoturismo na estrada real: reflexão sobre o planejamento e gestão do segmento no Polo Diamantina (MG)

\begin{abstract}
O Brasil é um país de recursos naturais e com enorme potencial para todas as modalidades de turismo, porém, muitos de seus ecossistemas, e o cerrado em especial, estão ameaçados pela prática de um ecoturismo irresponsável que poderá vir agravar essa situação. Apesar desse risco, o ecoturismo configura-se, no momento, como uma das mais importantes alternativas de desenvolvimento econômico sustentável, desde que sejam utilizados racionalmente os recursos naturais em visitações monitoradas, sem comprometer a sua capacidade de renovação e sua conservação.
\end{abstract}

Ainda segundo Neiman e Rabinovici (2002), o cerrado tem potencial para oferecer observação de fauna e flora, safáris fotográficos e possui diversas belezas paisagísticas, despontando o ecoturismo como uma atividade que pode promover o desenvolvimento econômico e social dessas regiões. Sendo assim, Diamantina, por estar localizada no bioma cerrado e por possuir diversas belezas naturais, pode despontar como um forte destino para a prática dessa atividade.

Segundo a pesquisa elaborada por Vieira (2012), intitulada "O desenvolvimento do mercado de Ecoturismo na cidade de Diamantina", percebeu-se claramente o que já apontam outras pesquisas: o principal atrativo turístico natural é o Parque Estadual do Biribiri com a Cachoeira da Sentinela e a Cachoeira dos Cristais.

Segundo Vieira (2012) em se tratando das modalidades de ecoturismo praticadas em Diamantina e região aponta-se para uma característica peculiar do destino. No quesito das modalidades de ecoturismo praticadas na região de Diamantina, muitos respondentes apontaram as atividades de Caminhada e Caminhada de longo curso, Rapel, Cicloturismo, Cavalgada, Turismo fora de estrada, Trekking. Metade dos respondentes mencionaram as atividades de Escalada, Espeleoturismo, Montanhismo e Tirolesa. Poucos mencionaram Arvorismo, Canionismo e Cachoeirismo, Canoagem e Observação da vida selvagem.

Percebe-se que existe uma variedade muito significativa de modalidades praticadas, e pela diversidade existente, muitas outras ainda poderiam ser trabalhadas para serem oferecidas de forma segura ao ecoturista que procura por essas atividades, além de gerar benefícios econômicos às comunidades envolvidas e a valorização da cultura local.

A relação entre as modalidades e o benefício para a comunidade demonstra equilíbrio entre as opiniões dos respondentes, pois muitos responderam que essas modalidades trazem benefícios, ressaltando que economicamente há um retorno para a comunidade local com as despesas e consumo dos turistas. Outro benefício significativo que deve ser apontado é o alto índice de realização de atividades de ecoturismo pela comunidade local, que frequentam, por exemplo, o Parque Estadual do Biribiri, fazendo caminhadas e visitando cachoeiras. De acordo com Vieira (2012), a comunidade diamantinense se beneficia bastante dos atrativos do Parque, pois são frequentadores assíduos. A empresa Quintal Radical ressaltou que no Circuito de arvorismo do Quintal em Curralinho, nas atividades de Rapel e tirolesa a mão de obra é de monitores locais. Assim, é significativa também a geração de emprego e renda para a 
Vieira, G.D.; Bulhões, N.G.; Bulhões, T.G.

comunidade.

As atividades como a caminhada de longo curso, o cicloturismo e a cavalgada trazem grande benefício, pois utilizam serviços de apoio totalmente nas comunidades, como meios de hospedagem, contratação de condutores, alimentação, serviços de muleiros gerando recursos diretamente para a comunidade.

Ainda nesse contexto, baseado especificamente em números da "Pesquisa de Demanda Turística Real de Diamantina e Região", realizada semestralmente pelo Curso de Turismo da UFVJM por meio das edições já concretizadas (2009-1, 2009-2, 2010-1, 2010-2, 2011-1, 2011-2 e 2012-1), apresenta-se informações significativas acerca do mercado de ecoturismo local.

No quesito Motivação Principal da viagem a Diamantina, em todas as edições os atrativos ligados à cultura são apresentados como principais. Porém, nesse tema a Pesquisa aponta também dados interessantes acerca do meio natural. Nas edições de 2009 (1 e 2), do total de 516 entrevistados, 21 turistas tiveram a natureza como motivação principal de visita; número que subiu para 35 nas edições de 2010, na qual 264 turistas participaram; para 45 em 2011 dentre 297 entrevistados nas duas edições e apenas 13 turistas entre os 142 participantes, no primeiro semestre de 2012. Esses dados podem ser mais bem visualizados no Gráfico 1:

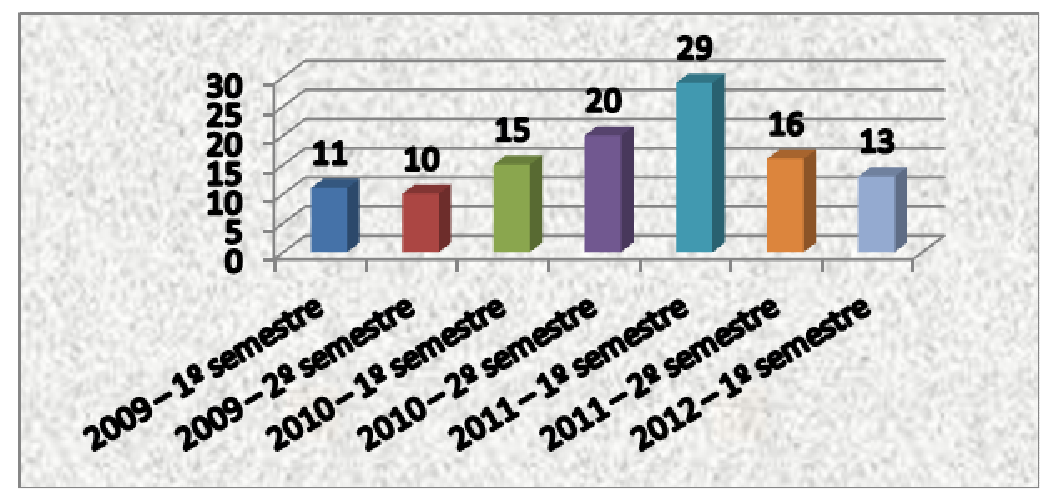

Gráfico 1: Número de turistas que tiveram natureza como motivação principal. Graph 1: Number of tourists who have nature as their primary motivation.

Fonte: elaboração própria a partir de Medaglia e Silveira, 20091 e 2, 20101 e 2, 20111 e 2, 20121.

Source: Own elaboration from Medaglia and Silveira, 20091 e 2, 20101 e 2, 2011 e 2, 20121.

Percebe-se que a natureza é, ainda, motivação secundária, considerando que o público da cidade de Diamantina menciona Cultura, Arquitetura e Vesperata como motivações principais de suas visitas. Mesmo assim, é possível indicar os principais atrativos naturais visitados mencionados nas pesquisas que são: Parque Estadual do Biribiri - PEB, Cachoeiras, Gruta do Salitre, Caminhos dos Escravos, Parque Estadual do Itambé, Parque Estadual do Rio Preto, Parque Nacional das Sempre Vivas, Serra dos Cristais e Serra do Espinhaço.

Nesse contexto ainda, buscando especificamente dados relacionados ao meio natural, quando questionados sobre o que Ihes causou encantamento em Diamantina, 
Paisagens do ecoturismo na estrada real: reflexão sobre o planejamento e gestão do segmento no Polo Diamantina (MG)

nas edições de 2009 ( 1 e 2), do total de 516 entrevistados 81 turistas responderam que foi a natureza, seguidos por 43 nas edições de 2010, na qual 264 turistas participaram, 62 visitantes nas edições de 2011 dentre 297 entrevistados nas duas edições e, por fim apenas 20 visitantes no primeiro semestre de 2012 entre os 142 entrevistados.

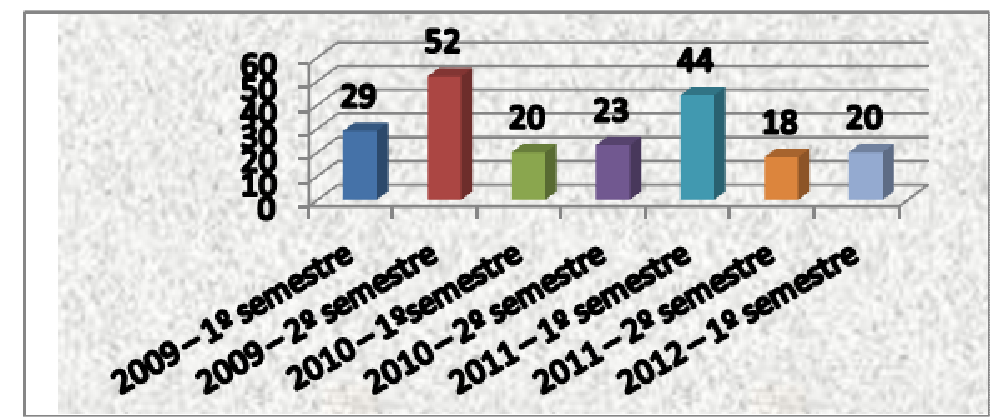

Gráfico 2: Número de turistas que se encantaram com a natureza em Diamantina.

Graph 2: Number of tourists enthralled with nature in Diamantina.

Fonte: elaboração própria a partir de Medaglia e Silveira, 20091 e 2, 20101 e 2, 20111 e 2, 20121.

Source: Own elaboration from Medaglia and Silveira, 20091 e 2, 20101 e 2, 20111 e 2, 20121.

\section{As Paisagens da Estrada Real e seu uso para o Ecoturismo}

O termo paisagem é carregado de significâncias e possui diversos conceitos, dentre os mais superficiais e os mais complexos, Oliveira (2007) destaca algumas das principais considerações cientificas acerca da palavra.

O termo "paisagem" foi introduzida na ciência pelo geobotânico, Alexander Von Humboldt, no início do século XIX, no sentido de "característica total de uma região terrestre" (Metzger, 2001). O seu conceito na ciência é aprofundado dentro de várias proposições onde se destacam: ecologia da paisagem (Troll, 1971), geossistemas (Sotchava, 1977), ecodinâmica (Tricart, 1977, 1979) e geografia física global (Bertrand, 1971) (OLIVEIRA et al, 2007, p. 88).

Como é possível perceber para uma completa análise da paisagem é necessário considerar processos técnicos de pesquisa, suas características geológicas, geormorfológicas, entre outro. Oliveira baseado em outros pesquisadores aponta outros aspectos da paisagem que devem ser considerados para sua análise.

O mapeamento das unidades de paisagem considera os atributos abióticos, bióticos e antrópicos (Bertrand, 1978; Bolós, 1981), ou seja, efetua uma síntese cartográfica dos diferentes temas que compõe a paisagem, como: geologia, clima, geomorfologia, pedologia, vegetação e uso da terra (Martins et al., 2002) (OLIVEIRA et al, 2007, p. 88). 
Este estudo aprofundado permite tratar não só dos aspectos de competência da visão, como sua beleza e cores, mas também permite entender sobre a formação da paisagem enquanto sistema ecológico.

A metodologia de paisagem possibilita descrever não só a beleza cênica, porém também o grau de estabilidade do sistema ecológico. A pesquisa da paisagem para o ecoturismo integra os diferentes componentes naturais (relevo, condições climáticas, solo, cobertura da vegetação, etc.) e avalia suas inter-relações com as características do destino turístico (OLIVEIRA et al, 2007, p. 87).

O artigo não faz uma análise aprofundada da paisagem como propõe Oliveira, consideramos paisagem como uma categoria de estudo da geografia que permite uma avaliação a partir de uma imagem que pode ser contemplada por meio da observação. Sendo assim, o artigo pretende apenas por meio da observação identificar as características da paisagem da região tendo em vista a prática do ecoturismo, ou seja, apontar atividades do ecoturismo que tem condições de serem desenvolvidas na região devido a suas peculiaridades.

Considerando o tratamento da paisagem desta forma, por meio da observação encontramos diversas bibliografias, que datam de diferentes períodos históricos, acerca das paisagens da região. Como já apresentado, a Estrada Real e a região de Diamantina foi explorada por viajantes, bandeirantes, que registraram não só a fauna, flora e riquezas, mas também suas percepções sobre as paisagens que compuseram suas viagens.

Sobre o trecho objeto desse artigo, que vai de Diamantina à Itapanhoacanga, distrito de Alvorada de Minas existem vários relatos de antigos viajantes que vieram desbravar a região, entre tantos destacamos Spix e Martius que percorreram o caminho por volta do ano de 1818. E também Felício dos Santos que elaborou o livro Memórias no Districto Diamantino em 1868.

Spix e Martius deixa claro sua percepção acerca da paisagem do trecho analisado e do encantamento que ela proporciona, emoção esta que até hoje é sentida pelos turistas que visitam a região como foi apontado anteriormente.

Quase parece que a natureza escolheu para a região ordinária dessas pedras preciosas os mais esplêndidos campos e os guarneceu com as mais lindas flores. Tudo que até agora havíamos visto de mais belo e soberbo em paisagens, parecia incomparavelmente inferior diante do encanto que se oferecia aos nossos olhos admirados. Todo o Distrito Diamantino parece um jardim artisticamente plantado, a cuja alternativa de românticos cenários alpestres, de montes e vales, se aliam mimosas paisagens de feição idílica. (...)

Sente-se o viajante, nesses deliciosos jardins, atraído de todos os lados por novos encantos e segue extasiado pelos volteios do caminho sempre nas alturas que o leva de uma a outra das belezas naturais. Volven- 
Paisagens do ecoturismo na estrada real: reflexão sobre o planejamento e gestão do segmento no Polo Diamantina (MG)

do o olhar do pacífico e variegado ambiente para a distância, o espectador vê-se todo contornado por altas montanhas rochosas que, iluminadas pelos ofuscantes raios solares, refletem uma luz resplandecente de seus vértices brancos, recortados em forma maravilhosa, aqui ameaçam desmoronar, ou, ali em amontoados terraços uns sobre os outros, puxam para o azul etéreo do céu, ou abrem-se profundos vales, patenteando abismos sombrios, onde alguma torrente montanha abre caminho com estrondo (SPIX E MARTIUS, 1981, P. 27).

Foi também devido à magnitude e importância da paisagem regional que Diamantina recebeu da Organização das Nações Unidas para a Educação, Ciência e Cultura - UNESCO o titulo de Patrimônio Cultural da Humanidade, cuja justificativa é ressaltada por Braga e Machado (2010, p.39) visto que "seu conjunto urbano é precioso testemunho da adaptação de modelos europeus a uma cultura original, tão perfeitamente integrada à paisagem severa e grandiosa".

Tendo em vista a importância da paisagem para a região pretendemos destacar as suas características que permitem o desenvolvimento do ecoturismo. As imponentes montanhas, precipícios, os campos, rios e cachoeiras são ambientes onde a atividade se desenvolve.

De acordo com o Ministério do Turismo o ecoturismo permite o uso do meio ambiente de diversas formas para desenvolver a atividade.

No âmbito do Ecoturismo observa-se a possibilidade de desenvolvimento de uma grande variedade de atividades. Caracterizam-se pela relação com a natureza, seja com a fauna, a flora, as formações rochosas, as paisagens, os espetáculos naturais extraordinários, e até mesmo vários deles ou todos ao mesmo tempo (BRASIL, 2010, p. 27).

A fim de apontar quais são essas atividades o Ministério criou a umas descrição dessas atividades (Tabela 1).

Para identificar os locais que acolhem aos critérios para a realização das atividades do ecoturismo extraímos do site do Instituto Estrada Real ${ }^{3}$ os atrativos naturais que atendem às atividades apontadas pelo Ministério do Turismo, lembrando que os municípios pesquisados são Diamantina, Serro e Alvorada de Minas. No site os atrativos naturais e histórico-culturais são listados juntos, porém consideramos apenas os atrativos em meio natural (Tabela 2).

São no total 24 atrativos naturais nos três municípios, sendo que Serro contém 11 deles, Diamantina outros 10 e Alvorada de Minas 3 atrativos. É um grande número de atrativos co potencial para serem explorados e trabalhados pelo turismo, e é essa analise, de quais e como esses atrativos vem sendo trabalhados que será apresentada com o diagnóstico a seguir. 
Tabela 1: Atividades praticadas no âmbito do ecoturismo.

Table 1: Activities performed within the scope of ecotourism.

\begin{tabular}{|c|c|}
\hline ATIVIDADE & $\bar{A} \mathbf{A}$ \\
\hline \multirow{4}{*}{$\begin{array}{l}\text { Observação de Fauna } \\
\text { (Relaciona-se com o } \\
\text { comportamento e habi- } \\
\text { tats de determinados } \\
\text { animais) }\end{array}$} & $\begin{array}{l}\text { Aves - atividade conhecida como birdwatching. O País ocupa o tercei- } \\
\text { ro lugar no mundo em matéria de diversidade no gênero, com um total } \\
\text { de } 1.832 \text { espécies, das quais } 234 \text { endêmicas. }\end{array}$ \\
\hline & $\begin{array}{l}\text { Mamíferos - o Brasil, que possui um número significativo de espécies } \\
\text { de mamíferos do mundo, apresenta algumas espécies consideradas } \\
\text { ícones da nossa fauna, como a onça-pintada, o tamanduá-bandeira, a } \\
\text { anta e o lobo-guará. }\end{array}$ \\
\hline & $\begin{array}{l}\text { Peixes - a observação geralmente ocorre pela flutuação ou mergulho, } \\
\text { com ou sem o uso de equipamentos especiais, em ambientes mari- } \\
\text { nhos ou de água doce. }\end{array}$ \\
\hline & $\begin{array}{l}\text { Répteis e anfíbios - considerado o primeiro em espécies de anfíbios e } \\
\text { o quarto em répteis, destaca-se no País a observação de salaman- } \\
\text { dras, sapos, rãs, pererecas, tartarugas, jacarés, lagartos, cobras. So- } \\
\text { bre esse assunto, apontam-se os projetos brasileiros para a conserva- } \\
\text { ção da tartaruga marinha e do tracajá. }\end{array}$ \\
\hline Observação de Flora & $\begin{array}{l}\text { Permite compreender a diversidade dos elementos da flora, sua forma } \\
\text { de distribuição e as paisagens que compõem um bioma, devendo es- } \\
\text { tar associada às possibilidades de interação com a fauna silvestre e- } \\
\text { xistente na localidade e região. Os usos tradicionais das comunidades } \\
\text { locais sobre as plantas (usos medicinais, cosméticos, ornamentais) } \\
\text { despertam muito interesse, podendo ampliar as experiências dos visi- } \\
\text { tantes e promover o uso sustentável de elementos que integram as } \\
\text { áreas visitadas. }\end{array}$ \\
\hline $\begin{array}{l}\text { Observação de Forma- } \\
\text { ções Geológicas }\end{array}$ & $\begin{array}{l}\text { Atividade ainda tímida no País que consiste geralmente em caminha- } \\
\text { da por área com características geológicas peculiares e que oferecem } \\
\text { condições para discussão da origem dos ambientes (geodiversidade), } \\
\text { sua idade e outros fatores, por meio da observação direta e indireta } \\
\text { das evidências das transformações que ocorreram na esfera terrestre. }\end{array}$ \\
\hline $\begin{array}{l}\text { Visite } \\
\text { (Esp }\end{array}$ & $\begin{array}{l}\text { Atividade recreativa originada da exploração de cavidades subterrâ- } \\
\text { neas, também conhecida por espeleologia - estudo das cavernas. }\end{array}$ \\
\hline $\begin{array}{l}\text { Observação Astronô- } \\
\text { mica }\end{array}$ & $\begin{array}{l}\text { Observação de estrelas, astros, eclipses, queda de meteoros, em lo- } \\
\text { cais preferencialmente com reduzida influência de iluminação artificial. }\end{array}$ \\
\hline Merg & $\begin{array}{l}\text { Mergulho no mar, rios, lagos ou cavernas cc } \\
\text { snorkel e nadadeiras, sem equipamentos autôn }\end{array}$ \\
\hline Caminhadas & $\begin{array}{l}\text { Percursos a pé em itinerário predefinido. Existem caminhadas de um } \\
\text { ou mais dias com a necessidade de carregar parte dos equipamentos } \\
\text { para pernoite em acampamentos ou utilizando meios de hospedagem, } \\
\text { em pousadas ou casas de família. }\end{array}$ \\
\hline Trilhas Interpretativas & $\begin{array}{l}\text { Conjunto de vias e percursos com função vivencial, com a apresenta- } \\
\text { ção de conhecimentos ecológicos e socioambientais da localidade e } \\
\text { região. Podem ser autoguiadas por meio de sinalização e mapas ou } \\
\text { percorridas com acompanhamento de profissionais, como Guias de } \\
\text { Turismo e Condutores Ambientais Locais. }\end{array}$ \\
\hline Safáris I & $\begin{array}{l}\text { Itinerários organizados para fotografar paisagens singulares ou ani- } \\
\text { mais que podem ser feitos a pé ou com a utilização de um meio de } \\
\text { transporte. }\end{array}$ \\
\hline
\end{tabular}

Fonte: Brasil (2010, p.30). Source: Brasil (2010, p.30). 
Tabela 2: Atrativos naturais de Diamantina, Serro e Alvorada de Minas.

Table 2: Natural Attractions of Diamantina, Serro e Alvorada de Minas.

\begin{tabular}{|c|c|c|}
\hline MUN. & ATRATIVO & DESCRIÇÃO \\
\hline \multirow{10}{*}{ DIAMANTINA } & $\begin{array}{c}\text { CACHOEIRA DAS } \\
\text { FADAS }\end{array}$ & $\begin{array}{l}\text { A Cachoeira é circundada por densa mata de transição e de } \\
\text { galeria e afloramentos rochosos, possui queda de } 25 \mathrm{~m} \text { for- } \\
\text { mando um poço propício ao banho. O acesso ao local pode } \\
\text { ser feito por um trecho de estrada e, depois, por uma trilha } \\
\text { de pedras com descida acentuada. Localizado a } 49 \mathrm{~km} \text { da } \\
\text { sede em direção ao Distrito de Conselheiro da Mata. }\end{array}$ \\
\hline & $\begin{array}{l}\text { CACHOEIRA DOS } \\
\text { REMÉDIOS }\end{array}$ & $\begin{array}{l}\text { Cachoeira circundada por densa mata de transição e de ga- } \\
\text { leria e formações rochosas, possui queda de } 20 \mathrm{~m} \text { formando } \\
\text { um belo poço propício ao banho. Localizada a } 15 \mathrm{~km} \text { do Se- } \\
\text { de. }\end{array}$ \\
\hline & GRUTA DO SALITRE & $\begin{array}{l}\text { Conjunto de grandes formaç̃os rochosas com embasamen- } \\
\text { tos cristalinos, formando cânions, que se dividem em salões } \\
\text { da Gruta do Salitre, o maior com } 64 \mathrm{~m} \text { de largura e } 5 \mathrm{~m} \text { de } \\
\text { altura. As formas pontiagudas e esculturais remetem à ar- } \\
\text { quitetura das igrejas góticas. Localizada a } 9 \mathrm{~km} \text { de diamanti- } \\
\text { na e a } 1 \mathrm{~km} \text { do distrito de Curralinho. }\end{array}$ \\
\hline & $\begin{array}{l}\text { CACHOEIRA DO } \\
\text { TELÉSFORO }\end{array}$ & $\begin{array}{l}\text { Considerada a mais bonita cachoeira do distrito de Conse- } \\
\text { Iheiro Mata, com praia de areia branca, circundada de densa } \\
\text { mata ciliar e de transição, formada por corredeiras, que de- } \\
\text { ságuam em poços propícios ao banho. Localizada no Distrito } \\
\text { de Conselheiro Mata, à } 36 \mathrm{~km} \text { da Sede. }\end{array}$ \\
\hline & $\begin{array}{l}\text { GRUTA MONTE } \\
\text { CRISTO }\end{array}$ & $\begin{array}{l}\text { A Gruta possui abertura horizontal de aproximadamente } \\
15 \mathrm{~m} \text { de altura por } 25 \mathrm{~m} \text { de largura, dois amplos salões com } \\
\text { água corrente e embasamento cristalino. O local serviu de } \\
\text { cenário para a novela Irmãos Coragem da rede Globo. Loca- } \\
\text { lizada a } 12 \mathrm{~km} \text { de Diamantina. }\end{array}$ \\
\hline & $\begin{array}{c}\text { PARQUE ESTADUAL } \\
\text { DE BIRIBIRI }\end{array}$ & $\begin{array}{l}\text { Possuí } 17.130 \text { hectares, onde ainda não foi definido a sua } \\
\text { posição como parque, mas é um lugar de vasta vegetação e } \\
\text { fauna, além de cachoeiras e poços. }\end{array}$ \\
\hline & $\begin{array}{c}\text { CACHOEIRA DA } \\
\text { TOCA }\end{array}$ & $\begin{array}{l}\text { Cachoeira circundada por formações rochosas e vegetação } \\
\text { de cerrado com queda de } 15 \mathrm{~m} \text { de altura e } 15 \mathrm{~m} \text { de largura, } \\
\text { formando pequenos filetes de água e um grande poço propí- } \\
\text { cio ao banho, que chega a } 8 \mathrm{~m} \text { de profundidade. Localizada } \\
\text { próxima à Sede - } 10 \text { min de caminhada. }\end{array}$ \\
\hline & $\begin{array}{c}\text { CACHOEIRA DOS } \\
\text { CRISTAIS }\end{array}$ & $\begin{array}{l}\text { Cachoeira circundada por formação rochosa e cerrado. Pos- } \\
\text { sui duas quedas sequenciais de aproximadamente } 5 \mathrm{~m} \text {, for- } \\
\text { mando um poço propício ao banho. Localizada à } 14 \mathrm{Km} \text { da } \\
\text { sede. }\end{array}$ \\
\hline & $\begin{array}{l}\text { SÍTIO ARQUEOLÓGI- } \\
\text { CO DO BATATAL }\end{array}$ & $\begin{array}{l}\text { Encontram-se várias pinturas rupestres sobre a fauna repre- } \\
\text { sentativa da região: capivaras, veados e peixes - não há um } \\
\text { estudo que afirme com exatidão a idade das pinturas. O sítio } \\
\text { fica a } 49 \mathrm{~km} \text { de Diamantina, é aconselhável o acompanha- } \\
\text { mento de um guia local. }\end{array}$ \\
\hline & $\begin{array}{l}\text { CAMINHO DOS } \\
\text { ESCRAVOS }\end{array}$ & $\begin{array}{l}\text { A estrada vai da sede do município ao distrito de Mendanha, } \\
\text { era usada pelos tropeiros no transporte de cargas e dos dia- } \\
\text { mantes. O caminho cruza o Parque Estadual do Biribiri e } \\
\text { áreas particulares. Os principais remanescentes } \\
\text { (principalmente trechos calçados) encontram-se nas extre- } \\
\text { midades do caminho. Aconselhável acompanhamento de um } \\
\text { guia. Calçamento de pedras construído por escravos distan- } \\
\text { te } 2 \mathrm{~km} \text { da sede, sentido BR- } 367 \text { que vai para Araçuaí. }\end{array}$ \\
\hline
\end{tabular}

Continua... 

...continuação.

\begin{tabular}{|c|c|c|}
\hline \multirow{11}{*}{ SERRO } & $\begin{array}{l}\text { CACHOEIRA DO } \\
\text { CARIJÓ }\end{array}$ & $\begin{array}{l}\text { Situada a } 3 \mathrm{~km} \text { de Milho Verde, a Cachoeira do Carijó tem } \\
8 \mathrm{~m} \text { de queda e possui um grande poço com água limpa. } \\
\text { Ideal para banho, seu acesso é feito seguindo a estrada } \\
\text { principal de Milho Verde, no sentido Milho Verde - Serro. }\end{array}$ \\
\hline & RIO JEQUITINHONHA & $\begin{array}{l}\text { Rio cuja nascente está entre Milho Verde e Capivari. O } \\
\text { Rio Jequitinhonha faz parte da história do surgimento de } \\
\text { Milho Verde, bem como, outros lugarejos, graças ao ga- } \\
\text { rimpo de Ouro e Diamantes. }\end{array}$ \\
\hline & $\begin{array}{l}\text { CACHOEIRA DO } \\
\text { MOINHO }\end{array}$ & $\begin{array}{l}\text { Próximo a Milho Verde e de fácil acesso, está a cachoeira } \\
\text { do Moinho. Após uma sucessão de piscinas naturais, que } \\
\text { correm sobre uma lage, as águas desabam em duas } \\
\text { grandes quedas, para mais abaixo formar o rio Jequitinho- } \\
\text { nha. }\end{array}$ \\
\hline & $\begin{array}{l}\text { CAMINHO MILHO } \\
\text { VERDE AO POVOADO } \\
\text { DO VAÚ }\end{array}$ & $\begin{array}{l}\text { Antigo caminho que ligava Milho Verde ao vilarejo de Vau. } \\
\text { Trecho em campos abertos e matas fechadas. Existem } \\
\text { até hoje vestígios de calçamentos de pedras. Tem aproxi- } \\
\text { madamente } 9 \mathrm{Km} \text {. }\end{array}$ \\
\hline & $\begin{array}{l}\text { CACHOEIRA DO } \\
\text { LAGEADO }\end{array}$ & $\begin{array}{l}\text { E um dos principais atrativos de Milho Verde e um dos } \\
\text { mais visitados também. Distância de } 2 \mathrm{Km} \text { da cidade. }\end{array}$ \\
\hline & $\begin{array}{l}\text { CACHOEIRA DO } \\
\text { PIOLHO }\end{array}$ & $\begin{array}{l}\text { E uma das cachoeiras mais altas de Milho Verde com u- } \\
\text { ma queda livre de } 35 \text { metros. Utilizada para a prática de } \\
\text { rapel. Tem esse nome devido aos pequenos diamantes } \\
\text { que davam em seu leito, do tamanho de piolhos. Está a } 3 \\
\text { Km de Milho Verde. }\end{array}$ \\
\hline & $\begin{array}{l}\text { CAMINHO DE MILHO } \\
\text { VERDE Á TRÊS } \\
\text { BARRAS }\end{array}$ & $\begin{array}{l}\text { Trilha de calçamentos de pedras ligando Milho Verde á } \\
\text { Três Barras, que foi aberta por escravos. O Caminho é } \\
\text { feito por belos campos rupestres, passando por pequenas } \\
\text { cachoeiras e riachos de águas cristalinas. }\end{array}$ \\
\hline & PICO DO RAIO - SGRP & $\begin{array}{l}\text { Pico que está localizado na divisa de Capivari e São Gon- } \\
\text { çalo do Rio das Pedras. }\end{array}$ \\
\hline & $\begin{array}{l}\text { CACHOEIRA DO } \\
\text { COMÉRCIO }\end{array}$ & $\begin{array}{l}\text { Cachoeira situada dentro da cidade. Queda muito alta, } \\
\text { usada para a prática do rapel. }\end{array}$ \\
\hline & $\begin{array}{l}\text { CACHOEIRA DA } \\
\text { GROTA SECA }\end{array}$ & $\begin{array}{l}\text { Cachoeira com pequenas quedas, formando piscinas na- } \\
\text { turais em meio a muitas montanhas e matas. }\end{array}$ \\
\hline & $\begin{array}{l}\text { CACHOEIRA DO } \\
\text { PACU }\end{array}$ & $\begin{array}{l}\text { Cachoeira no meio de matas e com algumas piscinas na- } \\
\text { turais, tem como ponto de referencia um campo de fute- } \\
\text { bol. }\end{array}$ \\
\hline \multirow{3}{*}{$\begin{array}{l}\text { ALVORADA } \\
\text { DE MINAS }\end{array}$} & ALTO DO CRUZEIRO & $\begin{array}{l}\text { O Mirante proporciona uma bela visão panorâmica de to- } \\
\text { da a cidade e do pico do Itambé com sua vasta mata nati- } \\
\text { va ao seu entorno. Está localizado na entrada da cidade. }\end{array}$ \\
\hline & $\begin{array}{l}\text { CACHOEIRA DA } \\
\text { CAMPINA }\end{array}$ & $\begin{array}{l}\text { A cachoeira com quedas de até } 4 \mathrm{~m} \text { e águas cristalinas, } \\
\text { lindas formações rochosas, muitos poços e abundante } \\
\text { vegetação circundante. Está localizada no distrito de Ita- } \\
\text { panhoacanga. }\end{array}$ \\
\hline & RIO DO PEIXE & $\begin{array}{l}\text { O rio do Peixe corre formando cachoeiras, corredeiras, } \\
\text { piscinas naturais e cascatas (lugares de rara beleza - fau- } \\
\text { na e flora riquíssimas). Dentre as belezas naturais, desta- } \\
\text { camos o balneário Tanque do Carimbé e a Área de Prote- } \\
\text { ção Renascença. }\end{array}$ \\
\hline
\end{tabular}

Fonte: Elaboração própria adaptado de www.estradareal.org.br (2013).

Source: Authors, adapted from www.estradareal.org.br (2013). 
Paisagens do ecoturismo na estrada real: reflexão sobre o planejamento e gestão do segmento no Polo Diamantina (MG)

\section{Diagnóstico do Planejamento e Gestão do Ecoturismo em Diamantina e Região}

A cidade de Diamantina é polo e referencia do turismo regional, por isso acolhe sede de instituições de abrangência regional, é o caso do Instituto Estrada Real - IER, Circuito dos Diamantes e Instituto Estadual de Florestas - IEF, esses que mais se relacionam ao turismo, mas ainda tem-se como exemplo, o SEBRAE, EMATER, IDENE, etc.

Além dessas instituições, Diamantina também é sede dos receptivos turísticos que comercializam o destino e a região. São esses receptivos, Agência de Viagens e Turismo Minhas Gerais Ltda.; Agência Veredas do Espinhaço, ARM Turismo e Quintal Radical. Para este trabalho consideramos apenas estas empresas para diagnosticar as atividades que vem sendo oferecidas, mas é importante ressaltarmos que cada vez mais grupos independentes vêm praticando atividades como ciclismo, escalada, rapel e caminhada na região, porém como não existem dados e fontes oficiais para pesquisa, assim esses grupos foram desconsiderados. O levantamento e perfil desses grupos se faz como um interessante tema à ser pesquisado.

Nesse contexto, foram levados em consideração os atrativos envolvidos nos pacotes de ecoturismo comercializados pelos quatro receptivos, bem como as atividades desenvolvidas, nos primeiros municípios do Polo Diamantina da Estrada Real, como foi apontada anteriormente como foco do trabalho. O levantamento foi feito com base nos matérias de divulgação dos receptivos, seus folders informativos, para assim ter acesso às atividades que já são comercializadas, pois se o meio para este levantamento fosse uma pesquisa com os responsáveis pelos receptivos, talvez pudessem ser apontados atividades que vem sendo estudadas para comercialização, mas como ainda não estão no mercado por isso preferimos apenas a análise do que é divulgado e vendido.

Para uma melhor visualização foi construída a Tabela 3 para demonstrar o diagnóstico das atividades de ecoturismo comercializadas.

Os atrativos não estão sendo explorados em sua totalidade, apenas parte de seu potencial é explorado, na tabela de diagnóstico, é possível observar que o mesmo atrativo se enquadra em mais de uma atividade de ecoturismo, porém não são todos os tipos de atividades que são comercializadas, uma opção seria o conhecimento dos gestores dos receptivos turísticos para oferta opcional dessas atividades aos turistas, dessa forma seria conferido a esses produtos mais valor.

No levantamento dos atrativos do trecho foco são apontadas 13 cachoeiras e 2 rios, dentre as cachoeiras, apenas a do Telesforo é comercializada diretamente, outras como a dos Cristais e a do Moinho são associadas a outros atrativos.

Algumas das atividades listadas pelo MTur ainda não são praticadas na região, são elas, observação da fauna e da flora, observação astronômica e safári fotográfico, atividades que tem potencial visto que a região pesquisada se localiza na Serra do Espinhaço, e conta com grande número de espécies endêmicas da fauna e flora. Dos atrativos indicados no site ER dez deles não fazem parte dos pacotes comercializados, confirmando o potencial ainda não trabalhado. Isso ainda sem levar em consideração outros regiões e atrativos que tem muito potencial mais sem mínima estrutura turística, como é o caso do Parque Nacional das Sempre-Vivas. 
Tabela 3: A comercialização do ecoturismo no início do caminho dos diamantes da Estrada Real.

Table 3: The marketing of ecotourism at the beginning of the path of diamonds in the Royal Road.

\begin{tabular}{|c|c|c|c|}
\hline RECEPTIVO & PACOTES & ATRATIVOS & ATIVIDADES \\
\hline \multirow{3}{*}{$\begin{array}{l}\text { Veredas do } \\
\text { Espinhaço }\end{array}$} & $\begin{array}{l}\text { Diamantina } \\
\text { Natural }\end{array}$ & $\begin{array}{c}\text { Curralinho, Gruta do Salitre, } \\
\text { Parque Estadual do Biribiri, } \\
\text { Cruzeiro Luminoso, Cachoeira } \\
\text { da Sentinela, Pinturas } \\
\text { Rupestres. }\end{array}$ & $\begin{array}{c}\text { Observação de Formações } \\
\text { Geológicas, Visitas a } \\
\text { cavernas, Caminhadas, } \\
\text { Trilhas Interpretativas }\end{array}$ \\
\hline & Estrada Real & $\begin{array}{c}\text { Rio Jequitinhonha, Cachoeira } \\
\text { do Moinho, Cachoeira do } \\
\text { Carijó }\end{array}$ & $\begin{array}{l}\text { Mergulho Livre, Caminha- } \\
\text { das, Trilhas Interpretativas }\end{array}$ \\
\hline & $\begin{array}{l}\text { Cachoeira do } \\
\text { Telésforo }\end{array}$ & $\begin{array}{c}\text { Serra do Pasmar, Pedra da } \\
\text { Tromba d'Anta, Cachoeira do } \\
\text { Telésforo, Cachoeira das } \\
\text { Fadas }\end{array}$ & $\begin{array}{l}\text { Observação de Formações } \\
\text { Geológicas, Caminhadas, } \\
\text { Trilhas Interpretativas }\end{array}$ \\
\hline \multirow{3}{*}{ Minhas Gerais } & Curralinho & $\begin{array}{l}\text { Gruta do Salitre, Curralinho, } \\
\text { Serra do Espinhaço. }\end{array}$ & $\begin{array}{c}\text { Observação de Formações } \\
\text { Geológicas, Caminhadas, } \\
\text { Trilhas Interpretativas }\end{array}$ \\
\hline & $\begin{array}{c}\text { Parque Estadual } \\
\text { do Biribiri }\end{array}$ & Vila do Biribiri e cachoeiras. & $\begin{array}{l}\text { Caminhadas, Trilhas } \\
\text { Interpretativas }\end{array}$ \\
\hline & Estrada Real & Vau, Milho Verde, Serro & $\begin{array}{l}\text { Caminhadas, Trilhas } \\
\text { Interpretativas }\end{array}$ \\
\hline \multirow{4}{*}{ Quintal Radical } & Rota Curralinho & $\begin{array}{c}\text { Cruzeiro da Serra, Caminho } \\
\text { dos Escravos, Gruta do Salitre, } \\
\text { Curralinho. }\end{array}$ & $\begin{array}{c}\text { Observação de Formações } \\
\text { Geológicas, Visitas a } \\
\text { cavernas, Caminhadas, } \\
\text { Trilhas Interpretativas }\end{array}$ \\
\hline & $\begin{array}{c}\text { Rota Conselheiro } \\
\text { Mata }\end{array}$ & $\begin{array}{c}\text { Cachoeira das Fadas, } \\
\text { Cachoeira do Telésforo, } \\
\text { Distrito de Conselheiro Mata }\end{array}$ & $\begin{array}{l}\text { Caminhadas, Trilhas } \\
\text { Interpretativas }\end{array}$ \\
\hline & Rota Milho Verde & $\begin{array}{l}\text { São Gonçalo do Rio das } \\
\text { Pedras, Milho Verde - Cacho- } \\
\text { eira do Moinho e do Carijó }\end{array}$ & $\begin{array}{l}\text { Caminhadas, Trilhas } \\
\text { Interpretativas }\end{array}$ \\
\hline & $\begin{array}{c}\text { Cicloviagem na } \\
\text { Estrada Real }\end{array}$ & Diamantina a Ouro Preto & Trilhas Interpretativas \\
\hline \multirow{4}{*}{ ARM } & $\begin{array}{l}\text { Parque Estadual } \\
\text { do Biribiri }\end{array}$ & $\begin{array}{c}\text { Cachoeira da Sentinela, } \\
\text { Cachoeira dos Cristais, Vila do } \\
\text { Biribiri } \\
\end{array}$ & $\begin{array}{l}\text { Caminhadas, Trilhas } \\
\text { Interpretativas }\end{array}$ \\
\hline & Gruta do Salitre & Gruta do Salitre & $\begin{array}{c}\text { Observação de Formações } \\
\text { Geológicas, Visitas a caver- } \\
\text { nas, Trilhas Interpretativas }\end{array}$ \\
\hline & $\begin{array}{l}\text { Passeio à Milho } \\
\text { Verde }\end{array}$ & Milho Verde - foco histórico & $\begin{array}{l}\text { Caminhadas, Trilhas } \\
\text { Interpretativas }\end{array}$ \\
\hline & $\begin{array}{l}\text { Cachoeira do } \\
\text { Telésforo }\end{array}$ & Cachoeira do Telésforo & $\begin{array}{c}\text { Caminhadas, Trilhas } \\
\text { Interpretativas, Mergulho }\end{array}$ \\
\hline
\end{tabular}

Fonte: Elaboração própria. Source: Authors.

Como é possível perceber os receptivos já oferecem várias opções de atividades do ecoturismo, mas ainda há muito potencial para ser explorado de maneira sustentável, e que gere não só um retorno financeiro, mas também no sentido da preservação 
Paisagens do ecoturismo na estrada real: reflexão sobre o planejamento e gestão do segmento no Polo Diamantina (MG)

e valorização do meio ambiente natural, histórico e cultural da região. Esse perfil de publico merece pacotes, roteiros e atrativos estruturados também para o ecoturismo, dessa forma acreditamos ter alcançado a intenção do artigo que é de diagnosticar a situação atual da gestão e comercialização do ecoturismo bem como apontar o grande potencial que há para ser trabalhado.

\section{Referências bibliográficas}

BRAGA, S.; MACHADO, J. Comunicação e cidades Patrimônio Mundial no Brasil. Brasília: UNESCO, IPHAN. 2010.

BRASIL. Diretrizes para uma politica nacional de ecoturismo. Brasília, Embratur/ Ibama, 1994.

BRASIL. Ministério do Turismo. Ecoturismo: orientações básicas. / Ministério do Turismo, Secretaria Nacional de Políticas de Turismo, Departamento de Estruturação, Articulação e Ordenamento Turístico, Coordenação Geral de Segmentação. 2. ed. Brasília: Ministério do Turismo, 2010.

CÉSAR, P.A.B.; et al. Ecoturismo: caminhos do futuro - Ministério do Turismo, AVT/IAP, NT/USP. São Paulo: IPSIS, 2007.

INSTITUTO ESTRADA REAL, Conheça o Instituto Estrada Real. Disponível em: $<$ http://www.institutoestradareal.com.br/institucional/apresentacao > Acesso em: 04 de julho de 2013.

INSTITUTO ESTRADA REAL. Estrada Real: Brasil. São Paulo: Empresa das Artes, 2005.

MARQUES, D.A.D. Estrada Real: Patrimônio Cultural de Minas Gerais (?) - Um estudo de Diamantina e Serro. 170 f. Dissertação (Mestrado Profissional em Turismo) Centro de Excelência em Turismo, Universidade de Brasilia, Distrito Federal, 2009.

MITRAUD, S. Manual de Ecoturismo de Base Comunitária: ferramentas para um planejamento responsável. Brasília: WWF Brasil, 2003.

MORAES, W.V. Ecoturismo: um bom negócio com a natureza. Viçosa: Aprenda fácil, 2000. v.1

MOURÃO, R.M.F.(Org.) Manual de melhores práticas para o ecoturismo. Rio de Janeiro: FUNBIO: Instituto ECOBRASI, 2004.

NEIMAN, Z. (Org.). Meio ambiente, educação e ecoturismo. Barueri, SP: Manole, 2002.

RODRIGUES, A.B. Ecoturismo - limites do eco e da ética. In: Ecoturismo no Brasil: possibilidades e limites. São Paulo: Contexto, 2003.

SANTOS, J.F. Memórias no Districto Diamantino da Comarca do Serro Frio. Rio de Janeiro: Typographia Americana, 1868

SPIX; MARTIUS. Viagem pelo Brasil: 1817-1820; tradução Lúcia Furquim Lahmeyer. 4 ed. Belo Horizonte: Ed. Itatiaia; São Paulo: Ed. da Universidade de São Paulo, 1981. 
VIEIRA, G.D. O Desenvolvimento do Mercado de Ecoturismo na Cidade de Diamantina/MG. Relatório de Pesquisa de Iniciação Científica. Diamantina: UFVJM, 2012.

\section{Notas:}

INSTITUTO ESTRADA REAL, Conheça o Instituto Estrada Real. Disponível em: <http:// www.institutoestradareal.com.br/institucional/apresentacao > Acesso em: 04 de julho de 2013.

${ }^{2}$ Entre os dias 26 de agosto a 4 de setembro de 2002, a Organização das Nações Unidas promoveu em Johannesburgo, a Cúpula Mundial sobre o Desenvolvimento Sustentável, também conhecida como Rio+10. Esse evento reuniu representantes de 189 países, além da participação de centenas de Organizações Não Governamentais (ONGs). As discussões na Rio+10 não se restringiram somente à preservação do meio ambiente, englobou também aspectos sociais. Disponível em: http://www.brasilescola.com/geografia/rio-10.htm. Acesso dia: 29/03/2011.

${ }^{3}$ www.estradareal.org.br.

Gabriela Duarte Vieira: Universidade Federal dos Vales do Jequitinhonha e Mucuri, Diamantina, MG, Brasil.

Email: gabiduarte83@yahoo.com.br

Link para o currículo Lattes: http://lattes.cnpq.br/8646278535561064

Tainá Gonçalves Bulhões: Universidade Federal de Minas Gerais, Belo Horizonte, MG, Brasil.

Email: taina_gbulhoes@yahoo.com.br

Link para o currículo Lattes: http://lattes.cnpq.br/6772228461686706

Nauê Gonçalves Bulhões: Universidade Federal dos Vales do Jequitinhonha e Mucuri , Diamantina, MG, Brasil.

Email: nauegb@gmail.com

Link para o currículo Lattes: http://lattes.cnpq.br/7010523049833393

Data de submissão: 29 de julho de 2013

Data de recebimento de correções: 29 de julho de 2013

Data do aceite: 01 de setembro de 2013

Avaliado anonimamente 